\title{
Postoperatif pulmoner komplikasyonları öngörmede yaşam kalitesinin önemi
}

\author{
The role of health quality in predicting postoperative pulmonary complications
}

\author{
Aşkın Gülşen (D) \\ Dokuz Eylül Üniversitesi Tıp Fakültesi, Göğüs Hastalıkları Anabilim Dalı, İzmir, Türkiye
}

Öz

Amaç: Abdominal cerrahilerde postoperatif pulmoner komplikasyonlar (PPK), morbitide ve mortalitenin önemli bir nedenidir. Ayrıca hastanede yatış süresini uzatan önemli bir faktördür.

Preoperatif değerlendirme, komplikasyonların tahmin edilmesinde ve önlem alınmasında önemli bir yer oluşturmaktadır. Değerlendirme sıklıkla öykü, fizik muayene, akciğer grafisi, solunum fonksiyon testleri, gerekli olgularda arteriyel kan gazı, ve egzersiz testleri ile yapılmaktadır. Bu çalışmada, diğer değerlendirme parametrelerinden farklı olarak PPK'ı öngörmede yaşam kalitesinin önemini araştırmayı amaçladık.

Yöntem: Çalışmamıza Genel Cerrahi AD'da elektif batın cerrahisi yapılacak olan 124 hasta alınmıştır. Hastalar ameliyat öncesi 1 haftalık dönemde değerlendirilmiş ve nottingham sağlık profili (NSP) skoru hesaplanmıştır. Postoperatif 48.saat sonrasında semptomlar ve komplikasyonlar incelenerek, preoperatif NSP değerleri ile karşılaştırılmıştır.

Bulgular PPK görülen hastalarda NSP-total puanı ort. 125,71 $\pm 114,09$ puan ve görülmeyenlerde ort. $63,65 \pm 72,75$ puandı ( $p=0.002$ ). Fiziksel mobilite, ağrı, enerji düzeyi, duygusal reaksiyon, uyku durumu, ve sosyal izolasyon düzeylerine göre yapılan değerlendirmede emosyonel durum haricinde diğer tüm puanlar komplikasyon görülen hastalarda daha yüksek saptandı. Mortalite görülen hastaların ort. 209,31 $\pm 130,74$ puan olduğu görüldü. Hastalar NSP puanlarına göre grup-1 (0-49,9), grup-2 (50,0-99,9), grup-3 $(100-149,9)$ ve grup-4 (>150 puan) olarak sınıflandırıldı. Buna göre grup-4 olan hastalarda \%72,7 pulmoner komplikasyon görüldü $(p<0.001)$. Yine 150 puan ve üzeri olan hastalarda solunumsal komplikasyonlar 7,6 kat, solunum dışı komplikasyonlar ise 6,7 kat artmış bulundu.

Sonuç: Çalışmamız, hastaların NSP puanı 150 ve üzerinde olması durumunda komplikasyonların daha fazla olduğunu göstermiştir. Ayrıca NSP sağ kalımı da iyi predikte etmiştir. Bu sonuçlar ile NSP'nin preoperatif risk değerlendirmede yararlı olabileceği düşünülmüştür.

Anahtar Sözcükler: Elektif batın cerrahisi, nottingham sağlık profili, postoperatif pulmoner komplikasyonlar, yaşam kalitesi

\footnotetext{
Abstract parameters. that evolved in the postoperative 48th hour.

Yazışma Adresi: Aşkın Gülşen

Dokuz Eylül Üniversitesi Tıp Fakültesi, Göğüs Hastalıkları

Anabilim Dalı, İzmir, Türkiye

E-mail: askingulsen@hotmail.com

Makalenin Geliş Tarihi: 19.04.2018 Kabul Tarihi: 06.07.2018
}

Aim: Postoperative pulmonary complications (PPC) in abdominal surgeons is an important factor that prolongs the hospitalization period as well as is an important cause of morbidity and mortality. Preoperative evaluation is an important part of estimating complications and taking precautions. However, pulmonary function tests, arterial blood gases, and exercise tests are used in the evaluation. In this study, we aimed to investigate the importance of quality of life in predicting PPC different from other evaluation

Patients and Methods: 124 patients who were assigned for various elective abdominal procedures in department of surgery; were included in the study. Notthingham health profile (NHP) scores 1 week prior to the surgery were calculated for each patient and were compared to the pulmonary complications (PPC) 
Results: In patients with PPC mean NHP score was $125,71 \pm 114,09$ and in patients without PPC the score was found to be $63,5 \pm 72,75$. The difference among the groups was statistically significant. The patients were distributed in to 4 groups according to their score and in group 4 (>150) pulmonary complication rate was $72,7 \%(p<0.001)$. Patients were classified according to their NHP scores as group1 (0-49,9), group-2 (50,0-99,9), group-3 (100-149,9) and group-4 (150 points).Furthermore; in group-4; pulmonary complication frequency was 7,6 times greater than the others.

Conclusion: In the present study it is found that patients with a NHP score greater than 150 encountered complications more frequently. Therefore; it can be assumed that NHP scoring system can be used in preoperative evaluation and postoperative risk prediction.

Keywords: Elective abdominal surgery, postoperative pulmonary complications, nottingham health profile, health quality.

\section{Giriş}

Abdominal cerrahilerde Postoperatif pulmoner komplikasyonlar (PPK), morbitide ve mortalitenin önemli bir nedenidir. Ayrıca hastanede yatış süresini uzatan önemli bir faktördür (1). Preoperatif değerlendirme (PD), komplikasyonların tahmin edilmesinde ve önlem alınmasında önemli bir yer oluşturmaktadır. PD sıklıkla öykü, fizik muayene, akciğer grafisi, solunum fonksiyon testleri (SFT), gerekli olgularda arteriyel kan gazı (AKG), ve egzersiz testleri ile yapılmaktadır (2).

PD için son yıllarda çeşitli risk indeksleri geliştirilmiştir. Bunlar arasında Amerikan Anesteziyoloji Derneği (ASA) tarafından geliştirilmiş indeks ameliyat planlanan hastalarda sık olarak kullanılmaktadır (3). ASA sınıflaması hastaların genel fiziksel durumunu belirlemekte ve tüm hastanelerde $P D$ için sık olarak kullanılmaktadır. ASA sınıflaması-II ve üzerinde olan hastalarda PPK sıklığıyla birlikte diğer komplikasyonların da arttığı bilinmektedir. ASA skorlamasında mortalite insidansı; ASA-I'de $(\% 0,1)$, ASA-II'de $(\% 0,7)$, ASA-III'de $(\% 3,5)$, ASAIV'te $(\% 18,3)$, ASA-V'te $(\% 93,3)$ olduğu belirtilmektedir (3).

Ameliyat öncesi değerlendirmede hastaların fizik durumu kadar yaşam kalitesi de oldukça önemlidir. Nottingham sağlık profili (NSP), hastaların yaşam kalitesini değerlendiren ve içerisinde 6 bölüm bulunan bir testtir. Bu bölümlerde fiziksel yetenek, ağrı düzeyi, enerji düzeyi, duygusal reaksiyon, uyku düzeni ve sosyal izolasyon değerlendirilmektedir (4). Son yıllarda Short-Form Health Survey (SF-36) yaşam kalitesi anketi ile özellikle kardiyak cerrahiler ve postoperatif komplikasyonlar üzerine araştırmalar yapılmış, yaşam kalitesinin preoperatif değerlendirmede önemi vurgulanmıştır (5-7). Ancak günümüz literatüründe yaşam kalitesi ile PPK'ların karşılaştırılarak değerlendirildiği çalışma sayısı çok azdır.

Bu çalışmanın amacı, bir yaşam kalitesi anketi olan NSP'nin postoperatif pulmoner komplikasyonları öngörmede etkisini araştırmaktı.

\section{Gereç ve Yöntem}

Genel Cerrahi kliniğinde elektif batın cerrahisine alınacak olgular prospektif olarak postoperatif komplikasyonlar açısından izleme alınması planlandı. Çalışmaya alınacak hastalar çalışma hakkında bilgilendirilerek ve aydınlatılmış onam formu alındı. Acil operasyonlar, inguinal herni operasyonu, organ transplantasyonu, 90 gün içerisinde re-opere edilen hastalar, rejyonal ya da spinal anestezi uygulanan hastalar ve 18 yaş altı hastalar çalışmadan dışlandı. Ayrıca, lokal etik kuruldan çalışma için onay alınmıştır.

\section{Preoperatif değerlendirme}

Hastalar ameliyat öncesi son bir hafta içerisinde değerlendirildi. Tüm hastaların yaş, cinsiyet, boy, kilo gibi demografik bilgileri alındı. Ayrıca tüm hastaların preoperatif dönemde dijital görüntüleme sistemi ile postero-anterior akciğer grafileri çekildi ve radyoloji uzmanı tarafından değerlendirilerek raporlandı. Anestezistlerin preoperatif kayıtlarından hastaların ASA (Amerikan Society of Anesthesiologists) klasifikasyonuna göre sınıflamaları alındı. Class 1 (normal), class 2 (hafif), class 3 (orta), class 4 (ağır), class 5 (mortalite riski) olarak kaydedildi. Hastaların mevcut yaşam kalitesini değerlendirmek amacıyla preoperatif dönemde Notthingham sağlık profili hastalara uygulandı.

\section{Nottingham Sağlık Profili}

Hastanın emosyonel, sosyal ve fizik durumunun belirlenmesini sağlar. Anket iki bölümden oluşmaktadır. 1.bölüm: Altı grup altında 38 soru 
içermektedir. Her sorunun belli bir değeri vardır ve her grupta toplam puan 100'dür. Evet cevabı ile alınan puanlar hastadaki negatif özellikleri yansıtmaktadır. 2. Bölüm: Hastanın ev, iş, sosyal, cinsel hayatı, hobi ve tatil standartlarıyla ilgili 6 soru içermektedir. Bu sorular evet/hayır şeklindedir $(4,8)$. Hastalarımıza sadece 1. bölüm anketi uygulanmıştır (Tablo-1). Türkçe formun geçerliliğ ve güvenilirliği Küçükdeveci ve arkadaşları tarafından 2000 yılında yapılmıştır (9). Hastalar puanlara göre grup-1 (0-49,9), grup-2 $(50,0-99,9)$, grup-3 (100-149,9) ve grup-4 (>150 puan) olarak sınıflandırıldı.

Tablo-1. Nottingham sağlık profili, 1.bölüm

\begin{tabular}{|c|c|c|}
\hline \multirow{8}{*}{ Fiziksel Yetenek } & 1. Sadece ev içinde yürüyebiliyorum. & 11,54 \\
\hline & 2. Eğilmek zor geliyor. & 10,57 \\
\hline & 3. Hiç yürüyemiyorum. & 21,30 \\
\hline & 4. Merdiven inip çıkarken zorluk çekiyorum. & 10,79 \\
\hline & 5. Bir şeye uzanmak zor geliyor. & 9,30 \\
\hline & 6. Giyinmekte zorluk çekiyorum. & 12,61 \\
\hline & 7. Uzun süre ayakta kaldığım zaman zorluk çekiyorum. & 11,20 \\
\hline & 8. Dışarıda yürümek için yardım gerekiyor. & 12,69 \\
\hline \multirow{8}{*}{ Ağrı düzeyi } & 1. Geceleri ağrım oluyor. & 12,90 \\
\hline & 2. Dayanılmaz ağrım var. & 19,74 \\
\hline & 3. Pozisyon değiştirmek ağrıya neden oluyor. & 9,31 \\
\hline & 4. Yürürken ağrım oluyor. & 11,22 \\
\hline & 5. Ayaktayken ağrım oluyor. & 8,96 \\
\hline & 6. Devamlı ağrım var. & 20,86 \\
\hline & 7. Merdiven inip çıkarken ağrım oluyor. & 5,83 \\
\hline & 8. Otururken ağrım oluyor. & 10,49 \\
\hline \multirow{3}{*}{ Enerji Düzeyi } & 1. Her zaman yorgunum. & 39,20 \\
\hline & 2. Her şey zor geliyor. & 36,80 \\
\hline & 3. Kısa zamanda güçten düşüyorum. Enerjim tükeniyor. & 24,00 \\
\hline \multirow{9}{*}{ Duygusal Reaksiyon } & 1. Olaylar beni yıpratıyor. & 10,47 \\
\hline & 2. Hayatımdan memnum değilim. & 9,31 \\
\hline & 3. Kendimi sinirli ve gergin hissediyorum. & 7,22 \\
\hline & 4. Günler birbirine benzer, rutin bir şekilde geçiyor. & 7,08 \\
\hline & 5. Bugünlerde kolayca öfkeleniyorum. & 9,76 \\
\hline & 6. Kontrolümü kaybettiğimi düşünüyorum. & 13,99 \\
\hline & 7. Üzüntü ve endişe uyumama engel oluyor. & 13,95 \\
\hline & 8. Hayatın yaşanmaya değmez olduğunu düşünüyorum. & 16,21 \\
\hline & 9. Kendimi bunalımda, depresyonda hissederek uyanıyorum. & 12,01 \\
\hline \multirow{5}{*}{ Uyku Düzeni } & 1. Uyumak için uyku verici ilaç kullanıyorum. & 22,37 \\
\hline & 2. Sabah çok erken saatte kalkıyorum. & 12,57 \\
\hline & 3. Gecenin çoğunu uyanık geçiriyorum. & 27,26 \\
\hline & 4. Uykuya dalmak uzun zaman alıyor. & 16,10 \\
\hline & 5. Geceleri iyi uyuyamıyorum. & 21,70 \\
\hline \multirow{5}{*}{ Sosyal İzolasyon } & 1. Kendimi yalnız hissediyorum. & 22,01 \\
\hline & 2. İnsanlarla iletişim kurmayı zor buluyorum. & 19,36 \\
\hline & 3. Bana yakın kimsenin olmadığını düşünüyorum. & 20,13 \\
\hline & 4. İnsanlara yük olduğumu düşünüyorum. & 22,53 \\
\hline & 5. İnsanlarla iyi geçinmek zor geliyor. & 15,97 \\
\hline
\end{tabular}




\section{Postoperatif değerlendirme}

Hastalar postoperatif dönemde 48.saatte tekrar değerlendirildi ve bir haftalık izleme alındı. 48.saatten fazla yoğun bakımda bulunan hastaların ekstübasyon saati ve gelişen komplikasyonlar anestezi dosyasındaki notlardan alındı. Serviste izlenen tüm hastaların solunum semptomları tekrar sorgulandı. Postoperatif görülen tüm komplikasyonlar, solunumsal ve solunum dışı olarak kaydedildi. Solunumsal komplikasyonlar; atelektazi, bronkospazm, reentübasyon, plevral effüzyon, pulmoner emboli, solunum yetmezliği, uzamış mekanik ventilasyon, $\mathrm{KOAH}$ alevlenme, pnömoni, ARDS, pulmoner ödem olarak kabul edildi (Tablo-2). PPK görülen olgular göğüs hastalıkları ve anestezi hekimleri tarafından değerlendirilerek ek tedavileri sağlandı. Postoperatif 1 aylık dönemde ölen hastalar kaydedildi.

\section{Istatistiksel Analiz}

Yapılan anketlerle elde edilen veriler SPSS for Windows 14.0 istatistik programına yüklendi ve istatistiksel analizleri yapıldı. Analizde her PD indeksleri kendi içerisinde komplikasyon sıklığını belirleme gücü, eğri altı chi-square testi ile odds ratio'ları belirlenerek bakıldı. Güven aralığı ise Miettinen formülü ile hesaplandı. PPK'a etki eden faktörler Ki kare(c2) analizi ile, gruplanmış veriler arasındaki farklılıklar student-t testi ile, parametrik koşulları yerine getirmeyen ve ölçümle belirlenen parametreler ise Mann Whitney-U testi ile değerlendirildi. Postoperatif komplikasyonları belirleyen indekslerin komplikasyon sıklığını belirleme gücü; eğri altında Ki kare (c2) analizi ile Odds Ratio'ların ölçülmesi ve \%95 düzeyinde güven aralığı ise Miettinen formülü ile hesaplandı. Sonuçların tümü \%95'lik güven aralığında ve anlamlılık $p<0.05$ düzeyinde değerlendirildi. Ek olarak, ROC eğrisi ile NSP puanının duyarlılık ve seçiciliği analiz edildi.

\section{Bulgular}

Çalışmamıza elektif batın cerrahisi planlanan 124 hasta alındı. Olguların demografik verileri, preoperatif risk indekslerinin dağılımı, hastaların klinik özellikleri ve operasyon türleri Tablo-1'de gösterilmektedir. Hastaların 63'ü $(\% 50,8)$ erkek, 61 'i $(\% 49,2)$ kadındı. Olguların yaş ortalaması 56,7 \pm 15,6 /yıl (yaş aralığı 19-86) idi. Hastaların ASA değerlendirmesine göre dağılımı ise ASA-I (\%38,7), ASA-II $(\% 45,2)$, ASA-III $(\% 15,3)$ ve ASAIV $(\% 0,8)$ idi. Tüm batın operasyonlarında 45 $(\% 36,2)$ hastada en az bir PPK görüldü. Takip eden 1 ay içerisinde $9(\% 7,2)$ hasta hayatın kaybetti. Abdominal cerrahilerde en sık görülen PPK plevral efüzyondu (23/124 - \%18,5) ve atelektaziydi (12/124 - \%9,7). Efüzyon olan hastalar, takip eden dönemde progresyon göstermemesi ve minimal olması nedeniyle ek girişim gerektirmedi (Tablo-3).

\section{Nottingham sağlık profili ve PPK ile ilgili sonuçlar}

Fiziksel yetenek, ağrı düzeyi, enerji düzeyi, duygusal reaksiyon, uyku düzeni ve sosyal izolasyon alt başlıklarına ait median değerler Tablo-3'de verilmiştir. Sonuçlara bakıldığında PPK görülen hastalarda ortalama NSP puanların daha yüksek olduğu görülmüştür (125,7'e 63,6 puan, $\mathrm{p}=0.002)$. Hastalarda duygusal reaksiyon hariç diğer alt başlıkların ortalamaları PPK görülenlerde daha yüksekti (Tablo-4). Ayrıca, elektif laparoskopik cerrahi uygulanacak olan hastaların preoperatif dönemde yaşam kalitelerinin diğer hastalara göre daha iyi olduğunu $(46,14 \pm 58,89)$, komplikasyon görülen $(125,71 \pm 114,09)$ ve yoğun bakıma alınan $(119,18 \pm 100,10)$ olguların preoperatif yaşam kalitelerinin daha kötü olduğunu da göstermiştir. Ayrıca postoperatif takipte kaybedilen olguların $(209,31 \pm 130,74)$, preoperatif NSP değerlerinin oldukça düşük olduğu da gözlemlenmiştir (Tablo-5).

ROC eğrisi ile yapılan detaylı analizde, NSP puanı 149,95 olması durumunda duyarlılık \%57,1 ve seçiciliği \%91,6 bulunmuştur (Tablo-6). Alt başlıkların ROC eğrisi ile yapılan analizlerinde ise duyarlılık \%33,3-64,1 ve seçicilik \%60,0-89,4 arasında değişmektedir (Tablo-7, Resim-1).

Duyarlılık ve seçicilik analizi sonrası hastalar 4 gruba ayrılmıştır, NSP 150 puan ve üzerinde olan hastaların \%72,7'sinde pulmoner komplikasyon görülmüştür (Tablo-8). Bu gruplamaya göre postoperatif dönemde kaybedilen olgular değerlendirildiğinde; NSP 150 puan ve üzeri olan ve PPK görülen 5 hasta $(\% 22,7)$ takipte eden 30 gün içerisinde kaybedildi $(p<0.001)$ (Tablo-9). Ayrıca NSP 150 üzeri olduğunda (odds ratio, $[\mathrm{OR}]=7,62$ ve $\quad \mathrm{p}<0.001) \quad$ solunumsal komplikasyonlar sık görülmüştür, ASA ile karşılaştırıldığında ise, ASA 3 ve üzeri olgularda $(\mathrm{OR}=7,06$ ve $\mathrm{p}<0.001)$ PPK daha sık görüldü (Tablo-10). Ek olarak ASA skorunun 3 ve üzerinde olmasıyla atelektazi $(p<0.01)$, solunum yetmezliği $(p<0,001)$, uzamış mekanik ventilasyon $(p<0.006)$ ve pnömoni $(p<0.04)$ skorlamada 3 ve altında olanlara göre daha sık görülmüştür. 


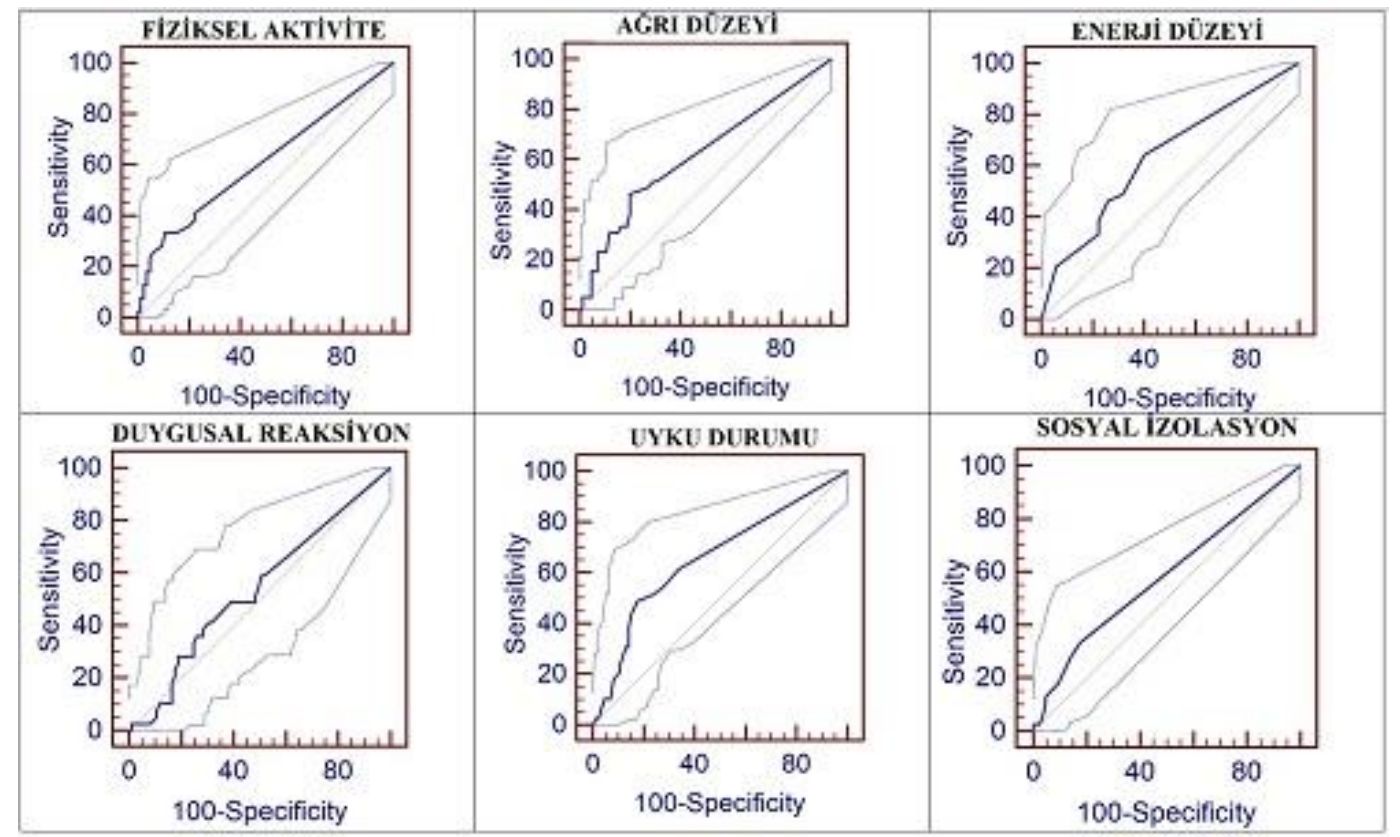

Resim-1. Nottingham sağlık profili duyarlılık ve seçiciliği

\section{Indeksler ve Mortalite}

Çalışmada postoperatif 1 ay sonunda 124 hastadan 9'u $(\% 7,2)$ kaybedildi. Bu hastaların $5^{\prime} \mathrm{i}$ erkek $(\% 55,6), 4$ 'ü $(\% 44,4)$ ise kadındı. Yaş ortalamaları 70,78 \pm 10,0/yıl (yaş aralığı 54-85) ve VKI $23,62 \pm 5,14 \mathrm{~kg} / \mathrm{m}^{2}$ idi. Ayrıca 6 hasta malignite nedeniyle opere edilirken, 2 hasta ileus, 1 hastaysa intraabdominal lenfadenopati ve tanı amacıyla opere edildi. Hastalardan 5 'i üst abdominal cerrahi, 4'ü ise alt abdominal cerrahi uygulanmıştı. Ortalama operasyon süreleri ortalama 298,33 \pm 99,40 /dk olduğu hesaplandı (145-480/dk aralığında). Hastalardan 8'inin $(\% 88,8)$ postoperatif yoğun bakım gereksinimi olurken, bir hasta postoperatif derlenme sonrasında servis izlemine alındı. Yoğun bakım izlem süreleri ortalama $67,11 \pm 51,02$ /saatti. Tüm hastalarda solunum ve solunum dışı komplikasyon mevcuttu. 4 hastada birden fazla solunumsal komplikasyon mevcuttu. Solunumsal komplikasyon olarak, 6 hastada uzamış mekanik ventilasyon, 5 hastada plevral effüzyon, 3 hastada solunum yetmezliği, 2 hastada ARDS, 1 hastada reentübasyon ve 1 hastada atelektazi saptandı. Solunum-dışı komplikasyon ise 3 hastada görüldü ve tüm hastalarda birden fazla komplikasyon mevcuttu. 4 hastada atrial fibrilasyon, 2 hastada sepsis, 2 hastada kanama, 2 hastada akut böbrek yetmezliği ve 1 hepatik ensefalopati saptandı.

Tablo-2. Solunumsal komplikasyonlar.

Atelektazi: Grafi ve dinleme bulgularıyla

Bronkospazm: Dinleme bulgularıla

Re-entübasyon: Postoperatif 24 saat içinde tekrar entübasyon gereksinimi olmasıyla

Plevral effüzyon: Grafi bulguları, oskültasyon ve matite varlığıyla

Solunum yetmezliği: Dinleme bulguları ve $\mathrm{PaO}_{2}<60 \mathrm{mmHg}$ ve/veya $\mathrm{PCO}_{2}>45 \mathrm{mmHg}$ olmasıyla

Uzamış mekanik ventilasyon: 72 saatten fazla mekanik ventilasyon ihtiyacının sürmesiyle

KOAH alevlenme: Preoperatif semptomsuz izlenen hastaların postoperatif öksürük, balgam ve nefes darlığı şikayetlerinin başlamasıyla

Pnömoni: Akciğer grafisinde yeni gelişen infiltrasyon olması, 38,3 dereceden yüksek ateş ve beyaz küre sayısının $>10.000$ üzerinde olmasıyla

ARDS/pulmoner ödem: Akciğer grafi bulguları ve PO2/FiO2 oranının 200'ün altında olmasıyla tanı konulmuştur. 
Tablo-3. Demografik veriler ve nottingham sağlık profili ( $\mathrm{n}: 124)$.

\begin{tabular}{lcll}
\hline Özellikler & $\mathbf{n}-(\%)$ & NSP & puan, median \\
\hline Cinsiyet & & Fiziksel yetenek & 8,80 \\
Kadın & $63-(50,8)$ & Ağrı düzeyi & 29,10 \\
Erkek & $61-(49,2)$ & Enerji düzeyi & 17,58 \\
& & Duygusal reaksiyon & 17,59 \\
PPK (yok) & $79-(63,7)$ & Uyku düzeni & 7,81 \\
PPK (var)* & $45-(36,3)$ & Sosyal İzolasyon & 8,83 \\
Plevral Efüzyon & $23-(18,5)$ & Ortalama & 15,53 \\
Atelektazi & $12-(9,7)$ & & \\
Uzamış MV & $11-(8,9)$ & & \\
Sol. Yetmezliği & $7-(5,6)$ & & \\
Bronkospazm & $5-(4,0)$ & & $54-(43,5)$ \\
Pnömoni & $4-(3,2)$ & NSP & $(24,1)$ \\
\hline ASA sınıflaması & & Grup-I & $30-(14,5)$ \\
ASA-I & $48-(38,7)$ & Grup-II & $18-(17,7)$ \\
ASA-II & $56-(45,2)$ & Grup-III & Grup-IV \\
ASA-III & $19-(15,3)$ & & \\
ASA-IV & $1-(0,8)$ & & \\
\hline
\end{tabular}

*Bazı hastalarda birden fazla PPK görülmüştür.

MV, mekanik ventilasyon; NSP, Nottingham sağlık profili, ASA,

PPK, postoperatif pulmoner komplikasyon

Tablo-4. Nottingham sağlık profili ve PPK gelişimi.

\begin{tabular}{lcccc}
\hline NSP & $\begin{array}{c}\text { PPK (yok) } \\
(\mathbf{n : 7 9 )}\end{array}$ & $\begin{array}{c}\text { PPK (var) } \\
(\mathbf{n}: \mathbf{4 5})\end{array}$ & min-max & *p-değeri \\
\hline Fiziksel yetenek & $4,13 \pm 9,83$ & $15,27 \pm 24,55$ & $0-100$ & 0.005 \\
Ağrı düzeyi & $6,80 \pm 13,93$ & $13,66 \pm 18,54$ & $0-78,13$ & 0.034 \\
Enerji düzeyi & $20,44 \pm 29,25$ & $39,47 \pm 39,40$ & $0-100$ & 0.006 \\
Duygusal reaksiyon & $15,55 \pm 18,40$ & $18,23 \pm 19,95$ & $0-86,01$ & 0.450 \\
Uyku düzeni & $12,36 \pm 23,26$ & $27,32 \pm 29,20$ & $0-100$ & 0.004 \\
Sosyal İzolasyon & $4,34 \pm 10,93$ & $11,74 \pm 19,86$ & $0-84,03$ & 0.025 \\
Ortalama & $63,65 \pm 72,75$ & $125,71 \pm 114,09$ & $0-548,17$ & 0.002 \\
\hline
\end{tabular}

*Student-t testi,

Tablo-5. Preoperatif nottingham sağlık profili puanları.

\begin{tabular}{lcccc}
\hline Özellikler & $\mathbf{n}$ & NSP Puanı \pm SD & \multicolumn{2}{c}{ Puan Aralığı } \\
\hline Laparoskopik cerrahi uygulanmış & 28 & $46,14 \pm 58,89$ & 0 & $-227,71$ \\
PPK görülmeyen Olgular & 79 & $63,65 \pm 72,65$ & 0 & $-466,51$ \\
Üst + Alt Abd.cerrahi uygulanmış & 96 & $97,85 \pm 99,70$ & 0 & $-466,51$ \\
Postop.yoğun bakıma alınmış & 27 & $119,18 \pm 100,10$ & 0 & $-411,70$ \\
PPK görülen olgular & 45 & $125,71 \pm 114,09$ & 0 & $-548,17$ \\
Postoperatif dönemde mortalite & 9 & $209,31 \pm 130,74$ & $78,61-411,70$ \\
\hline
\end{tabular}


Tablo-6. Nottingham sağlık profili duyarlılık ve seçiciliği.

\begin{tabular}{llccccc}
\hline NSP Puanı & Duyarlılık & $\mathbf{9 5 \%} \mathbf{C l}$ & Seçicilik & $\mathbf{9 5 \%} \mathbf{C l}$ & +LR & -LR \\
\hline$\geq 0$ & 100,00 & $59,0-100,0$ & 0,00 & $0,0-4,3$ & 1,00 & -- \\
$>39,2$ & 100,00 & $59,0-100,0$ & 47,62 & $36,6-58,8$ & 1,91 & 0,00 \\
$>39,51$ & 85,71 & $42,1-99,6$ & 47,62 & $36,6-58,8$ & 1,64 & 0,30 \\
$>47,58$ & 85,71 & $42,1-99,6$ & 52,38 & $41,2-63,4$ & 1,80 & 0,27 \\
$>54,85$ & 71,43 & $29,0-96,3$ & 52,38 & $41,2-63,4$ & 1,50 & 0,55 \\
$>61,09$ & 71,43 & $29,0-96,3$ & 55,95 & $44,7-66,8$ & 1,62 & 0,51 \\
$>63,2$ & 57,14 & $18,4-90,1$ & 58,33 & $47,1-69,0$ & 1,37 & 0,73 \\
$>149,95$ & 57,14 & $18,4-90,1$ & 91,67 & $83,6-96,6$ & $\mathbf{6 , 8 6}$ & $\mathbf{0 , 4 7}$ \\
$>152,84$ & 42,86 & $9,9-81,6$ & 91,67 & $83,6-96,6$ & 5,14 & 0,62 \\
$>227,71$ & 42,86 & $9,9-81,6$ & 97,62 & $91,7-99,7$ & 18,00 & 0,59 \\
$>281,46$ & 28,57 & $3,7-71,0$ & 97,62 & $91,7-99,7$ & 12,00 & 0,73 \\
$>346,86$ & 28,57 & $3,7-71,0$ & 98,81 & $93,5-100,0$ & 24,00 & 0,72 \\
$>398,06$ & 0,00 & $0,0-41,0$ & 98,81 & $93,5-100,0$ & 0,00 & 1,01 \\
$>466,51$ & 0,00 & $0,0-41,0$ & 100,00 & $95,7-100,0$ & -- & 1,00 \\
\hline
\end{tabular}

NSP: Notthingham sağlık profili; LR: olasılık oranı; Cl: Güven aralığı

*student-t test

Tablo-7. Nottingham sağlık profili duyarlılık ve seçiciliği.

\begin{tabular}{lcccc}
\hline NSP & Kriter & Duyarlılık & Seçicilik & p-değeri \\
\hline Fiziksel Aktivite & $>12,61$ & 33,3 & 89,4 & 0.005 \\
Ağrı Düzeyi & $>9,99$ & 46,2 & 80,0 & 0.034 \\
Enerji Düzeyi & $>0$ & 64,1 & 60,0 & 0.006 \\
Duygusal Reaksiyon & $>19,0$ & 41,0 & 69,4 & 0.45 \\
Uyku Durumu & $>21,7$ & 48,7 & 82,4 & 0.004 \\
Sosyal Izolasyon & $>0$ & 33,3 & 82,4 & 0.025 \\
\hline
\end{tabular}

NSP: Notthingham sağlık profili

Tablo-8. Nottingham sağlık profili, puanlara göre ppk gelişimi.

\begin{tabular}{|c|c|c|c|c|}
\hline \multirow{2}{*}{ NSP } & \multirow{2}{*}{ Grup } & PPK (yok) & PPK (var) & \multirow[t]{2}{*}{${ }^{\star}$ p-değeri } \\
\hline & & n $\quad(\%)$ & $(\%)$ & \\
\hline 0 - 49,99 & 1 & $40-(74,1)$ & $14-(25,9)$ & \\
\hline 50 - 99,99 & 2 & $20-(66,7)$ & $10-(33,3)$ & \\
\hline $100-149,99$ & 3 & $13-(72,2)$ & $5-(27,8)$ & \\
\hline$>150$ & 4 & $6-(27,3)$ & $16-(72,7)^{\star}$ & 0.001 \\
\hline
\end{tabular}

*student-t test 
Tablo-9. Nottingham sağlık profili, gruplara göre postoperatif mortalite (n:9).

\begin{tabular}{|c|c|c|c|c|}
\hline NSP & Grup & $\begin{array}{c}\text { Mortalite } \\
\mathbf{n} \quad(\%)\end{array}$ & $\begin{array}{c}\text { Mortalite (var) } \\
\text { n } \quad(\%)\end{array}$ & p-değeri \\
\hline $0-49,99$ & 1 & $54-(100)$ & 0 & \\
\hline $50-99,99$ & 2 & $28-(93,3)$ & $2-(6,7)$ & \\
\hline $100-149,99$ & 3 & $16-(88,9)$ & $2-(11,1)$ & \\
\hline$>150$ & 4 & $17-(77,3)$ & $5-(22,7)^{*}$ & ${ }^{*}<0.001$ \\
\hline
\end{tabular}

*student-t test

Tablo-10. ASA, nottingham sağlık profili ve postoperatif komplikasyonlar.

\begin{tabular}{lccc}
\hline Indeksler ve Solunumsal Komplikasyonlar & OR & \%95 Güven aralı̆̆ı & *p-değeri \\
\hline $\mathrm{ASA} \geq \mathrm{III}$ & 7,06 & $3,10<\mathrm{OR}<11,01$ & $<0.001$ \\
$\mathrm{NSP}=4 \quad(>150$ puan $)$ & 7,62 & $3,88<\mathrm{OR}<11,37$ & $<0.001$ \\
\hline
\end{tabular}

OR, odds-ratio; *eğri altı $\chi^{2}$ testi

\section{Tartışma}

Çalışmamı, preoperatif yaşam kalitesinin, hastalarda gelişebilecek PPK'ları öngörmede yararlı olabileceğini göstermektedir. PPK, hastaların morbidite ve mortalitesini artırarak hastanede kalış süresini uzatan önemli bir sorundur. Preoperatif değerlendirme ile risk taşıyan olguların erken belirlenmesi, hastaların postoperatif görülebilecek komplikasyonların azaltılması açısından önemlidir.

Son yıllarda özellikle kardiak cerrahilerde yaşam kalitesi anketleri (SF-36) ile yapılan araştırmalar yayınlanmıştır (10). Bu araştırmalarda yüksek postoperatif kardiyak riski olan ve düşük yaşam kalitesine sahip hastaların postoperatif yaşam kalitelerinin arttığı saptanmıştır. Bununla birlikte 70 yaş üstü hastaların daha fazla preoperatif komorbidite sahip olması nedeniyle postoperatif komplikasyonların daha fazla görüldüğü bildirilmiştir $(10,11)$. Çalışmamızda, PPK görülen olgularda preoperatif yaşam kaliteleri oldukça düşük bulunurken, postoperatif dönemde hayatını kaybeden olguların preoperatif yaşam kalitelerinin ise daha da düşük olduğunu ortaya koymuştur. Bu sonuçlar gözönüne alındığında, preoperatif düşük yaşam kalitesine sahip hastalarda, ameliyat kararı verilirken bu anketin yararlı olabileceğini düşündürmektedir.

ASA skorlaması, uzun yıllardır kullanılan, postoperatif mortaliteyi ve solunumsal komplikasyonları öngörmeye yardımcı, pratik olarak hesaplanabilen bir skorlamadır (3). Wong ve arkadaşları ASA-IV ve üzerinde olan hastalarda \%75 pulmoner komplikasyon ve \%18 ölüm bildirmiştir (12). ASA-IV ve V grubu hastalar, günlük hayatımızda acil cerrahi grubuna girmekte ve sadece yaşamı tehdit eden durumlarda uygulanmaktadır. Bu nedenle, çalışmamızda ASAIV ve üzeri sadece 1 hasta yer almıştır. ASA-III ve üzeri olan hastalarda ise solunumsal komplikasyonlar 7,06 kat daha sık görülmüştür. NSP puanı 150 ve üzeri olması durumunda da solunumsal semptomlar 7,62 kat daha sık görülmüştür. Bu birbirine yakın 2 sonuç preoperatif risk öngörmede ASA ve NSP'nin güçlerinin benzer olduğu göstermektedir.

Beşyüz hasta üzerinde yapılan bir çalışmada 80 yaşın üzerindeki olgularda postoperatif 30 günlük mortalite \%6,2 olarak bulunmuş ve bu hastaların \%1'inden azının ASA II sınıfında yeraldığı görülmüştür (13). Çalışmamızda 30 günlük mortalite \%7,2 idi, ancak literatür bilgisinden farklı olarak, hastalarımızın büyük bir çoğunluğu ASA-ı ve II grubu oluşturdu. Ayrıca mortalite görülen olguların \%66,6'sı malignite nedeniyle opere edilirken, \%88,8'i postoperatif uzamış yoğun bakım süresine (>48 saat) sahipti. Dolayısıyla bu olguların preoperatif yaşam kalitesinin daha düşük olması $(209,31 \pm 130,74$ puan $)$ da komplikasyonları öngörmede bu anketin yararını göstermektedir.

NSP, hastaları fiziksel mobilite, ağrı durumları, enerji düzeyi, duygusal reaksiyon, uyku durumu, ve sosyal izolasyon gibi durumlarını değerlendiren bir 
ankettir. Çalışmamızda, duygusal durum puanı haricinde diğer tüm değerlendirmelerin ortalama puanları komplikasyon görülen hastalarda daha yüksek saptandı. Bu sonuçla komplikasyon görülen olguların preoperatif hareket etme kabiliyetlerinin daha az, ağrılarının daha fazla, enerji düzeylerinin daha düşük, uyku kalitesi ve durumunun daha kötü olduğu ve kendilerini sosyal olarak daha izole hissettikleri sonucuna varıldı (Tablo-4). Araştırmamızın en önemli noktası, NSP puanının 150 puan ve üzeri olması durumunda hem komplikasyonların ve mortalitenin daha fazla görülmesidir. Elde ettiğimiz bu veriyi literatürde karşılaştırabileceğimiz bir çalışma bulunmamaktadır.

Ameliyat sonuçları ve NSP ile ilgili Thorsen ve arkadaşları tarafından 2002 yılında bir çalışma yapılmıştır (14). Kritik ekstremite iskemisi olan hastaların, revaskülarizasyon ameliyatından 3 ay sonra yaptıkları değerlendirmede ağrı skoru ve uyku durumlarında belirgin düzelme olduğunu bildirmiştir. Yapılan diğer bir çalışmada ise anjina pectorisi olan ve koroner arter bypass ameliyatı olan hastaların postoperatif hareket kabiliyeti, ağrı skoru ve enerji düzeyinde düzelme olduğu bildirilmiştir (15).

Bununla birlikte, akciğer kanserli hastalar üzerinde yeni yapılan bir araştırmada preoperatif egzersiz ve yaşam kalitesinin iyileştirilmesinin, hastaların hastanede yatış sürelerini ve postoperatif komplikasyonları azalttığı gösterilmiştir (16). Hwang ve arkadaşlarının yaptığı bir araştırmada, uyku bozukluğu olan hastalarda PPK daha sık görülmüş, ayrıca gece yapılan ölçümlerde 5 ve üzerinde oksijen desatürasyonu olan hastalarda postoperatif kardiyak, gastrointestinal ve kanama komplikasyonu da daha fazla saptanmıştır (17).

Çalışmamıza benzer sayılabilecek tek çalışma, diğer bir yaşam kalitesi olan St George Respiratory Questionnaire (SGRQ) ile yapılan bir araştırmadır. $\mathrm{Bu}$ araştırmada SGRQ total skoru $\geq 25$ olan hastalarda PPK'nın daha sık görüldüğü bildirilmiştir (18). NSP ile yapılan ve 215 hastayı kapsayan diğer bir çalışmada ise, açık kalp ameliyatı planlanan hastalar 3 yıllık sağ kalım açısından incelenmiştir. $\mathrm{Bu}$ araştırmada hastaların nefes darlığı derecesi (RR:2.80, \%95 güven aralığı = 1.2-6.5) ve NSP - enerji düzeyinin (RR:1.02, \%95 güven aralığı = 1.01-1.03) bağımsız 2 risk faktörü olduğu belirtilmiştir (19). Bununla birlikte NSP puanı, 75 yaş üstü ve kardiyak cerrahi geçirecek hastalarda, uzun dönem sağ kalımı yaş ve cinsiyet faktörleriyle birlikte benzer şekilde göstermiştir (20). Çalışmamızda 1 aylık sağ kalım \%92,8 olmak beraber, kaybedilen olguların preoperatif yaşam kaliteleri daha kötü olduğu görülmüştür.

Çalışmamızı kısıtlayan noktalarda bir tanesi, akut ve acil cerrahi girişimlerin çalışmaya dahil edilmeyişidir. Yine elektif kanser cerrahisi planan hastaların da yaşam kaliteleri ve psikolojik durumları da diğer hastalara göre farklılık göstereceği düşünülebilir. Ancak ameliyatların elektif planlanmış olması nedeniyle olası stresin tüm hastalar için benzer olduğu kabul edilmiştir. NSP skorlarına göre gruplandırılarak yaptığımız analizlerde özellikle NSP> 150 puan sınırı temel alındığında hastalarda hem PPK, hemde mortalite açısından riskin arttığını göstermiştir (Tablo-6, 7). Ayrıca mortalite görülen olguların \%66,6'sının kanser cerrahisi geçirmesi nedeniyle, bu grubun dışlanmasıyla yapılacak yeni bir çalışmaya intiyaç vardır. Ayrıca, hastaların preoperatif yaşam kalitesinin yükseltilmesinin komplikasyonlara ve mortaliteye etki edip etmeyeceği de ayrı bir araştırma konusu olabilir. NSP anketinin fiziksel yetenek, ağrı düzeyi, enerji düzeyi, duygusal reaksiyon, uyku düzeni, ve sosyal izolasyon gibi parametreleri değerlendirdiği gözönüne alındığında bu parametrelerin preoperatif dönemde iyileştirilmesinin faydalı olabileceği öngörülebilir. Bununla birlikte yaşam kalitesinin klinik önemini araştıran ve uzun vadeli sağ kalımı da değerlendiren yeni çalışmalara intiyaç bulunmaktadır.

\section{Sonuç}

NSP'nin preoperatif değerlendirmede ve risk ön görmede ASA kadar değerli olduğu, postoperatif pulmoner komplikasyon ve mortalite riskini öngörmede yararlı olabileceği sonucuna varılmıştır.

\section{Kaynaklar}

1. Lawrence VA, Dhanda R, Hilsenbeck SG, et al. Risk of pulmonary complications after elective abdominal surgery. Chest 1996; 110 (3): 744-50.

2. DeLisser HM, Grippi MA. Perioperative respiratory considerations in the surgical patients. In: Fishman AP (ed). Pulmonary Diseases and Disorders. 3rd ed: McGraw-Hill; 1998; 619-69. 
3. Wolters $\mathrm{U}$, Wolf $\mathrm{T}$, Stützer $\mathrm{H}$, et al. ASA Classification and perioperative variables as predictors of postoperative outcome. Br J Anaesth 1996; 77 (2): 217-22.

4. Hunt SM, McEwen J. The development of a subjective health indicator. Sociol Health IIIn 1980; 2 (3): 231-46.

5. Awdeh H, Kassak K, Sfeir P, et al. The SF-36 and 6-minute walk test are significant predictors of complications after major surgery. World J Surg 2015; 39 (6): 1406-12.

6. Kiebzak GM, Pierson LM, Campbell M, et al. Use of the SF36 general health status survey to document healthrelated quality of life in patients with coronary artery disease: effect of disease and response to coronary artery bypass graft surgery. Heart Lung 2002; 31 (3): 207-13.

7. Tabesh $\mathrm{H}$, Tafti HA, Ameri $\mathrm{S}$, et al. Evaluation of quality of life after cardiac surgery in high-risk patients. Heart Surg Forum 2014; 17 (6): 277-81.

8. Prieto L, Alonso J, Ferrer M, et al. Are results of the SF-36 health survey and the Nottingham Health Profile similar? A comparison in COPD patients. Quality of Life in COPD Study Group. J Clin Epidemiol 1997; 50 (4): 463-73.

9. Kücükdeveci AA, McKenna SP, Kutlay S, et al. The development and psychometric assessment of the Turkish version of the Nottingham Health Profile. Int J Rehabil Res 2000; 23 (1): 31-8.

10. Kurfirst $V$, Mokráček $A$, Krupauerová $M$, et al. Health-related quality of life after cardiac surgery--the effects of age, preoperative conditions and postoperative complications. J Cardiothorac Surg 2014; 9 (1): 46.

11. Westerdahl E, Jonsson M, Emtner M. Pulmonary function and health-related quality of life 1-year follow up after cardiac surgery. J Cardiothorac Surg 2016; 11 (1): 99.

12. Wong DH, Weber EC, Schell MJ, et al. Factors associated with postoperative pulmonary complications in patients with severe chronic obstructive pulmonary disease. Anesth Analg 1995; 80 (2): 276-84.

13. Djokovic JL, Hedley-Whyte J. Prediction of outcome of surgery and anesthesia in patients over 80. JAMA 1979; 242 (21): 2301-6.

14. Thorsen $\mathrm{H}$, McKenna S, Tennant A, et al. Nottingham health profile scores predict the outcome and support aggressive revascularisation for critical ischaemia. Eur J Vasc Endovasc Surg 2002; 23 (6): 495-9.

15. Peric VM, Borzanovic MD, Stolic RV, et al. Severity of angina as a predictor of quality of life changes six months after coronary artery bypass surgery. Ann Thorac Surg 2006; 81 (6): 2115-20

16. Steffens D, Beckenkamp PR, Hancock M,et al. Preoperative exercise halves the postoperative complication rate in patients with lung cancer: a systematic review of the effect of exercise on complications, length of stay and quality of life in patients with cancer. Br J Sports Med 2018; 52 (5): 344.

17. Hwang $D$, Shakir N, Limann B, et al. Association of sleep-disordered breathing with postoperative complications. Chest 2008; 133 (5): 1128-34.

18. Kim ES, Kim YT, Kang CH, et al. Prevalence of and risk factors for postoperative pulmonary complications after lung cancer surgery in patients with early-stage COPD. Int J Chron Obstruct Pulmon Dis 2016; 11 (1): 1317-26.

19. Chocron S, Etievent JP, Viel JF, et al. Preoperative quality of life as a predictive factor of 3-year survival after open heart operations. Ann Thorac Surg 2000; 69 (3): 722-7.

20. Jokinen JJ, Hippeläinen MJ, Hänninen T, et al. Prospective assessment of quality of life of octogenarians after cardiac surgery: factors predicting long-term outcome. Interact Cardiovasc Thorac Surg. 2008; 7 (5): 813-8. 